

\title{
Geografia, Paisagem e Corpo: o Corpo Enquanto Parte do Processo de Ressignificação do Ensino a Geografia
}

\author{
Geografía, Paisaje y Cuerpo: el Cuerpo como Parte del Proceso de \\ Resignificación de la Enseñanza a la Geografía
}

\section{Geography, Landscape and Body: the Body as Part of the Resignifying \\ Process of Geography Learning}

\section{Resumo}

O presente artigo tem a intenção de ecoar uma perspectiva de se trabalhar a geografia $2 \mathrm{x}$ e paisagem a partir da visão do corpo. Paisagem sempre teve um conceito positivista, ou seja, elemento estático, um conjunto de processos ecológicos. No nosso texto discorreremos outra perspectiva de paisagem, atualmente conhecida como uma abordagem holística, adentrando em aspectos multiculturais. Além de trazer conceitos trabalhados por Foucault sobre o corpo, de corpo como instrumento político. Fazendo assim, um encadeamento entre paisagem e corpo. E, a partir disso, mostrar como o ensino da geografia pode se dar de um outro olhar. Em suma, o artigo tentará tecer uma linha de ideias sobre esses conceitos, de paisagem dentro da geografia e corpo como paisagem.

Palavras-Chave: Geografia; Paisagem; Corpo.

\section{Resumen}

El presente artículo tiene la intención de accionar una perspectiva de trabajar la geografía, geografía y pasaje a partir de la visión del cuerpo. El paisaje siempre tuvo un concepto positivista, o sea, elemento estático, un conjunto de procesos ecológicos, en nuestro texto descubriremos otras perspectivas de paisaje, actualmente conocidas como abordajes holísticos, adentrándonos en aspectos multiculturales. Además de traer conceptos trabajados por Foucault sobre el cuerpo, del cuerpo como instrumento político. Haciendo así, un encadenamiento entre paisaje y cuerpo. Y, a partir de eso, mostrar como la enseñanza de la geografía puede darse con otra mirada. En suma, el articulo intentara tejer una línea de ideas sobre esos conceptos, de paisaje dentro de la geografía y del cuerpo como paisaje.

Palabras-Clave: Geografía; Paisaje; Cuerpo.

\begin{abstract}
This article intends to resound a perspective of teaching geography and landscape from the point of view of body. Landscape has always been a positivist concept, that is, a static element, a set of ecological processes. In this text we will discuss another landscape perspective, currently known as a holistic approach, including multicultural aspects. In addition, we bring out some concepts on the body discussed by Foucault: body as a political instrument. In doing so, we propose a link between landscape and body. As a result, we show how geography teaching can occur from another point of view. In short, this article will try to weave a line of ideas about these concepts: of landscape within geography and body as landscape.
\end{abstract}

Keywords: Geography; Landscape; Body.

Ana Flor Fernandes Rodrigues, Rairan de Almeida Silva 


\section{O Que nos Ensinavam e Ensinam na Escola sobre Geografia}

A geografia sempre foi entendida e vista como a disciplina que nos ensina o lugar das coisas, nos mostra os mapas, relevo, nos situa no mundo. Essa ideia vem da Geografia Tradicional, da geografia do positivismo. Quando perguntamos as pessoas, ou mesmo indo buscar nas nossas memórias, o que nossas lembranças mostram é o estudo cartográfico, do relevo, clima, vegetação, hidrografia, população e suas características, habitat rural, cidades, extrativismo, agricultura, indústrias. E ocorre apenas a transmissão de conteúdos. Atualmente - ou não - encontrados no livro didático.

Quando falamos da geografia positivista estamos falando do seu sentido mais amplo, não apenas o comteano, para demonstrar o que estamos tentando falar, o autor José William Vesentini (1987) nos dá esse subsídio teórico acerca do positivismo dentro da geografia que ainda insiste em permanecer nas práticas de ensino e entendimento da geografia, esse sentido do positivismo

[...] é o tomar um modelo elaborado a partir das ciências naturais, especialmente da física, como padrão de cientificidade; e o rejeitar a ideia de essência para enfatizar a crença na natureza incognoscível do real em seu âmago: a verdade científica, sempre relativa, seria por definição uma "aproximação" frente a esse real - a coisa em si ou o objeto real - , sendo que o critério para se avaliar o conhecimento está na sua eficácia instrumental; (VESENTINI, 1987, p. 63).

Dito isto, nos pegamos a pensar se de fato tais perspectivas ainda perduram nas escolas nos dias de hoje. Em conversa ${ }^{1}$ com outras pessoas, que estão inseridas no espaço escolar e trabalhando com o ensino da geografia, é notável em suas falas o que é a realidade e o que é esperado no ensino da geografia. Nos Parâmetros Curriculares de Geografia - Ensino Fundamental e Médio de Pernambuco do ano 2013 nos deparamos com a possível realidade do ensino.

O parâmetro em questão, de Pernambuco, tece um texto vislumbrando o que ensino da geografia pode vir a ser na complexa sociedade do século XXI. Em um dos pontos ele diz que

Mais do que nunca é necessário conhecer o mundo, é indispensável aprender a lidar com o enorme volume de informações produzidas sobre o mundo. É precisamente nesse aspecto que reside o papel a ser desempenhado pelo ensino de Geografia na escola. Fundamentalmente, sua tarefa é possibilitar aos estudantes questionarem, refletirem sobre e compreenderem o mundo em que vivem. (PARÂMETROS CURRICULARES DE GEOGRAFIA, 2013, p. 15-16).

Mas quando nos deparamos com a prática docente, não generalista, é, por vezes, longe do que está no papel. Como citado a cima, os relatos ouvidos, o

1 Ver o vídeo documentário “Geografia, paisagem e corpo". Assista em: https://bit.ly/2PEPrks.

Ana Flor Fernandes Rodrigues, Rairan de Almeida Silva 


\section{Ressignificação do Ensino a Geografia}

ensino da geografia não está ligado diretamente ao questionamento, à compreensão sobre o mundo que os cercam. Conseguimos afirmar com certa propriedade de que alguns profissionais da área, docentes de geografia, tanto do ensino fundamental - pedagogos e pedagogas - e professores e professoras do ensino fundamental dois e do ensino médio, não leem o parâmetro curricular de geografia, mesmo que lessem não se colocaria em prática. $\mathrm{O}$ texto escrito em certos momentos fogem de realidades, essas que não comportam o texto belo ali escrito.

De certo, é notável a importância desse texto, como deveria de ser o ensino da geografia e de como o alunado espera que ele seja. Um ensino que leve em consideração os "conhecimentos decorrentes de suas vivências espaciais e experiências, resultado de seus deslocamentos, pertencimentos e convivências com diferentes pessoas e grupos sociais" como bem pontua o texto do parâmetro curricular de geografia (2013).

É dentro dessa perspectiva que tentaremos nos aprofundar, da geografia que preocupa-se com as vivências espaciais dos corpos, de que eles se desloquem até o espaço escolar partilhem suas experiências, vivências e sentimentos com os demais. Que o corpo seja tratado enquanto ser político de pertencimento. Que ele olhe para o espaço e reconheça enquanto seu lugar. Uma das correntes teóricas que tratam da geografia dentro dessa concepção é a Geografia humanista, Rocha (2008) diz que essa vertente surge nos anos 70 e consolidase nos anos 80 e 90 com várias produções teóricas. O subjetivismo, a intuição, os sentimentos, o singular tornam-se a base das análises geográficas, instrumentos usados modelando a geografia cultural.

Mas os que vemos, infelizmente, nos espaços escolares, são profissionais que trabalham a geografia que sempre se pretendeu construir-se, como uma descrição da terra, de seus habitantes e das relações destes entre si e das obras resultantes que inclui toda ação humana sobre o planeta (ALVES, 2008). Continuam engessados na geografia positivista.

Como Josué de Castro (1984) em seu livro, Geografia da Fome, preocupasse em mostrar uma nova perspectiva sobre a geografia, propondo um novo discurso, um discurso sociopolítico dentro das camadas da geografia, tratando da fome, assunto delicado e de extrema importância. Mas se pararmos para pensar e refletir, como nos foram ensinados desde sempre, o objeto de estudo da geografia, de como ela nos é mostrada o tempo todo, diríamos que Josué de Castro estaria louco por trazer um assunto fora contexto - da geografia - para ser debatido dentro da geografia. Outros diriam que esse seria um assunto da sociologia, antropologia e das demais ciências sociais. Mas ele olha a geografia como lugar de várias possibilidades. E é assim que devemos olhar para ela, fitar nossos olhares para uma geografia que vai além, que vê o corpo como uma construção social, que ele é paisagem do espaço que está inserido.

\section{Paisagem: O Retrato}

Pinturas, natureza, cartões-postais, o ser belo. Essas são algumas das definições dadas ou que nos são dadas quando colocamos nossas mentes a pensar sobre paisagem, e sobre o que paisagem vem a ser. A construção 


\section{Ressignificação do Ensino a Geografia}

sociocultural do conceito "paisagem" dentro da perspectiva positivista perpassa o tempo e embebeda os corpos nos dias atuais. "Os conceitos de 'paisagem', 'região', 'lugar', 'espaço' e 'território' são exemplo de áreas privilegiadas pelos geógrafos na sua tarefa de conhecer e estudar a superfície da terra." (SALGUEIRO, 2001, p. 40).

Ainda, levando em consideração a fala de Salgueiro (2001), percebemos que as áreas da geografia, incluindo paisagem, sempre têm a vontade e necessidade de estudar a superfície da terra e suas especificidades geofísicas. Mas, ainda sim, encontramos dicotomias do conceito de paisagem dentro de uma perspectiva de geógrafos 'tradicionais', colocando a paisagem enquanto modificação do homem, os processos que a terra sofre com a inferência dos seres humanos.

Tradicionalmente, os geógrafos diferenciam entre a paisagem natural e a paisagem cultural. A paisagem natural refere-se aos elementos combinados de terreno, vegetação, solo, rios e lagos, enquanto a paisagem cultural, humanizada, inclui todas as modificações feitas pelo homem, como nos espaços urbanos e rurais. De modo geral, o estudo da paisagem exige um enfoque, do qual se pretende fazer uma avaliação definindo o conjunto dos elementos envolvidos, a escala a ser considerada e a temporalidade na paisagem. Enfim, trata-se da apresentação do objeto em seu contexto geográfico e histórico, levando em conta a configuração social e os processos naturais e humanos. (SCHIER, 2003, p. 80).

Quando falamos de paisagem cultural, aqui, é algo que está em movimento. São as formas e os discursos que movem o sentido de paisagem, a cultura é a paisagem de uma determinada sociedade, a paisagem é um lugar simbólico. "Assim, a paisagem se faz através da criação de uma unidade visual onde o seu caráter é determinado pela organização de um sistema de significação." (SCHIER, 2003, p. 84). Aqui entramos no campo das subjetividades. Onde a fala, o corpo, o som, os processos construtivos de uma sociedade tornam-se paisagem, ou melhor, resignifica-se o sentido de paisagem.

Visualizem a cena: um menino escuta um som, esse som vem de uma pedra, esse som o 'transporta' para um lugar, leva-o para uma viagem de sensações e sentimentos. Esse pedido feito a você, leitor, não foi um 'pedir por pedir', simplesmente. A partir do momento que você desloca seus sentimentos, suas vivências e experiências e realoca nessa imagem que propusemos a você, certamente queríamos mexer com seus sentimentos - sua subjetividade - cada pessoa que ler essa passagem certamente criará imagens diferentes, ou se aproximará da sensação que queríamos passar. Essa cena foi retirada do filme nacional $\mathrm{O}$ menino e o mundo, do Alê de Abreu.

Desse modo, quando pedimos para que você visualizasse a imagem do menino, certamente você também evocou algum som de sua memória, ou pensou em algum. Aqui estamos adentrando na perspectiva da paisagem sonora. Os sons podem nos trazer memórias e imagens mais 'fortes' do que as coisas que podemos ver ou tocar. Os sons agem sobre nossos corpos, fazendo 
Geografia, Paisagem e Corpo: o Corpo Enquanto Parte do Processo de

\section{Ressignificação do Ensino a Geografia}

com que esses vibrem e mergulhem em sentimentos diversos, "[...] as ondas sonoras estão presentes no espaço, ocupando-o e agindo sobre os seres humanos." (TORRES \& KOZEL, 2010, p. 126). E é nessa ótica dos corpos que queremos colocar a geografia. $O$ corpo é a tela, o retrato que todas essas visões se manifestam (figura 1).

Figura 1.

Fonte: Vinicius Rosa.

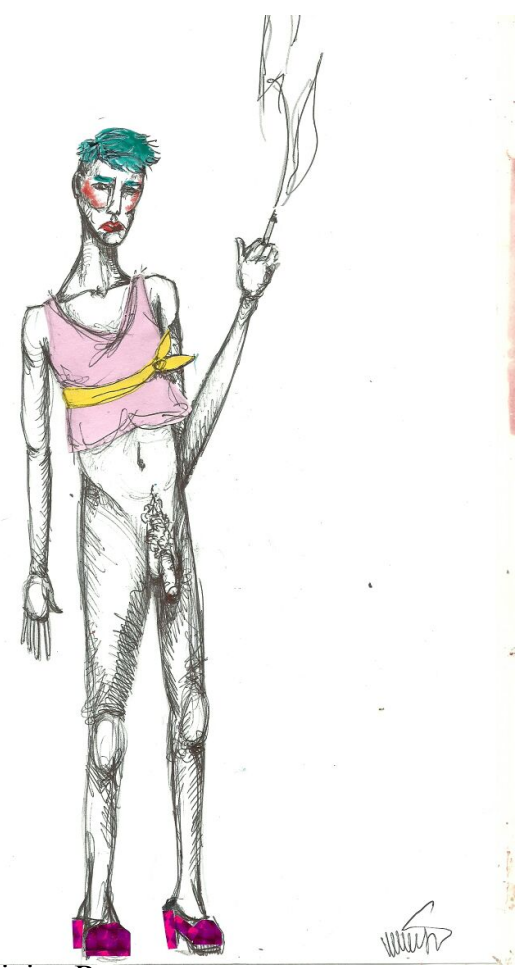

Corpo-Paisagem

Meu corpo é o contrário de uma utopia [...] Meu corpo é lugar irremediável a que estou condenado Michel Foucault

O corpo aqui será atravessado, muitas vezes, por uma arqueologia do saber proposta por Foucault (1972). No intuito de conseguirmos cavar os desdobramentos que ele (o corpo) viabiliza frente às paisagens. Principalmente pensando uma nova ótica ético-estética no que tange o ensino de geografia.

Gostaríamos de início, usar como exemplo alguns ocorridos que aconteceram durante uma pesquisa que realizamos para a disciplina de Pesquisa e Prática Pedagógica do nosso curso. Essa disciplina é voltada para a inserção das alunas e alunos do curso de pedagogia da UFPE a espaços específicos que se relacionam com o campo da educação.

\section{Criança-espaço/corpo: escola}

Nessa pesquisa, tivemos o privilegio de investigar sobre gestão escolar. Nossa ida à campo foi de frio na barriga, curiosidade e saída da zona de conforto que, muitas vezes, é a sala de aula na universidade. Além disso, de interpretação da atmosfera onde a escola se fazia presente. 
Geografia, Paisagem e Corpo: o Corpo Enquanto Parte do Processo de

\section{Ressignificação do Ensino a Geografia}

Durante a montagem do relatório, foi preciso fotografar parte do espaço. A todo momento crianças passavam enquanto tentávamos registrar as estruturas do lugar. Isso nos fazia, diversas vezes, refletir sobre como, de fato, as crianças deveriam estar, também, registradas naquele momento. Permitindo-nos observar como, inclusive, aquelas imagens poderiam se aproximar muito mais do que estávamos propondo se esses pequenos sujeitos fossem vistos de perto. Possibilitando compreender que o emaranhado da escola é feito de gente. Ou seja: essas precisam ser lidas enquanto parte da construção geográfica. Em outras palavras:

Todas essas derivas buscam apontar devires possíveis ao pensamento geográfico a partir da potência que a mirada sobre as imagens traz até ele, atravessando-o com novas possibilidades de criação; com um punhado de geografias menores que brotam das colisões, dos embates e das aproximações entre os estudos que apontam a forte presença de uma educação pelas imagens nos dias atuais e os pensamentos acerca do espaço geográfico que surgem dela. (OLIVEIRA JR, 2009, p. 27).

\section{0 corpo na favela}

Para pesarmos quais símbolos esses corpos carregam, precisamos refletir sobre um processo histórico no qual estamos inseridos para que se faça possível promover o debate. O Morro da Conceição é uma das maiores favelas do Recife, situada na zona norte da cidade, projeta consigo uma paisagem periférica singular e repleta de particularidades e significados para as pessoas que vivem e sobrevivem nesse espaço. A imagem a seguir (imagem 2) produz diversos significados, e é exatamente sobre esses significados que iremos nos debruçar, uma vez que pensar o corpo favelado é pensar espaço, economia, tempo, recursos didáticos e performances geográficas (figura 2).

Figura 2.

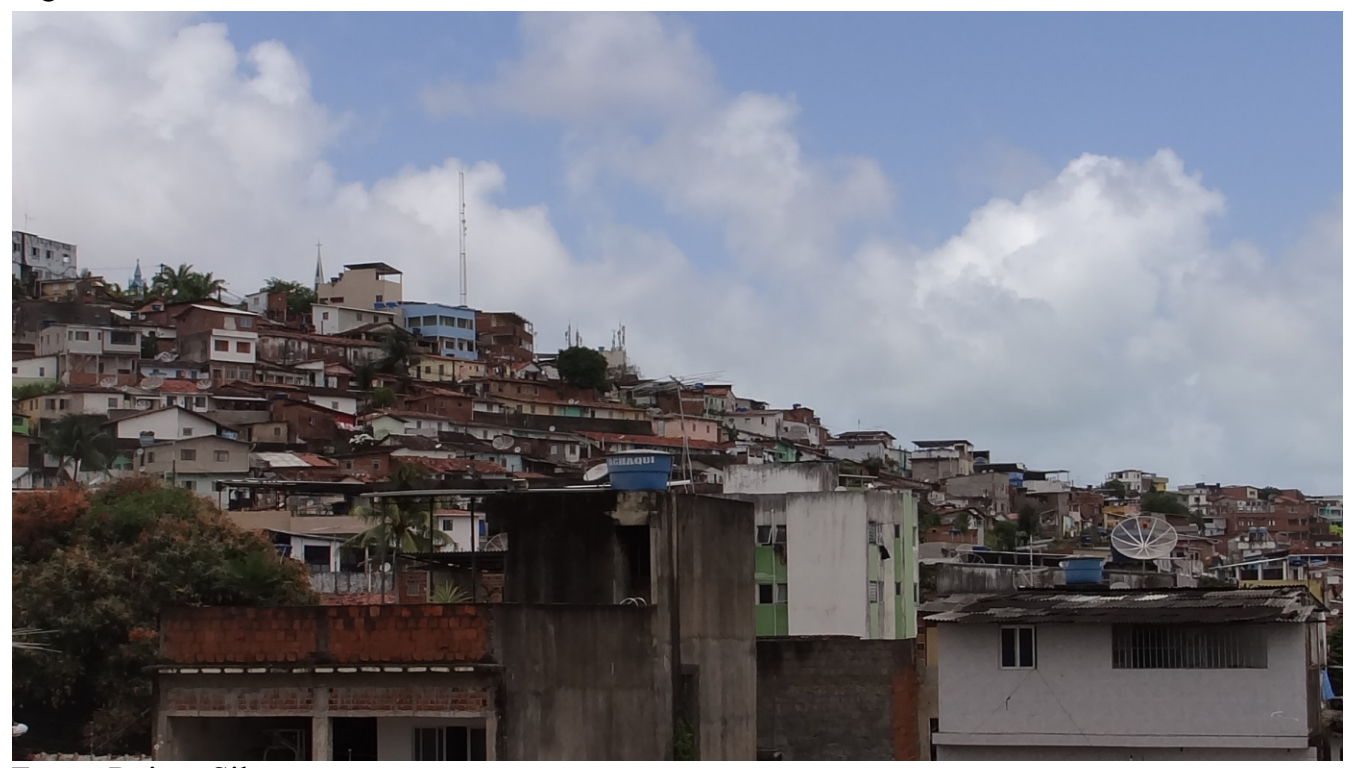

Fonte: Rairan Silva.

Ana Flor Fernandes Rodrigues, Rairan de Almeida Silva

Revista Latino-americana de Geografia e Gênero, Ponta Grossa, v. 9, n. 2, p. 293 - 303, ago. / dez. 2018. 
Geografia, Paisagem e Corpo: o Corpo Enquanto Parte do Processo de

\section{Ressignificação do Ensino a Geografia}

Por 'corpos favelados' entendemos os corpos que ocupam as favelas e que estão em constante disputa sobre um processo de docilização proposto, indevidamente, por parte de um Estado excludente que insiste em perpetuar dispositivos de poder. Visto que "em qualquer sociedade, o corpo está preso no interior de poderes muito apertados, que lhe impõe limitações, proibições ou obrigações", (FOUCAULT, 1987, p. 126).

Neste caso, os corpos estão sendo postos em um deslocamento de esteriotipação que costuma estar vinculada às margens. Nossa proposta, nesse eixo, é pensar a multiplicidade da geografia do corpo acentuado nos becos e vielas das favelas brasileiras. Percebendo a paisagem como ferramenta, permitindo que esses se sintam parte do espaço que ousam construir cotidianamente (figura 3). Dando, mais uma vez, um novo sentido ao que se entende por paisagem.

Precisamos desenhar novos mapas para compreender a geografia do copo, com sua espacialidade diferenciada, possível porque se move e, ao fazê-lo, ao mover-se, coloca em cena, diferentes possibilidades de abordagem, diferentes lugares, com diferentes perspectivas espaciais e temporais [...] (NÓBREGA, 2005, p. 612).

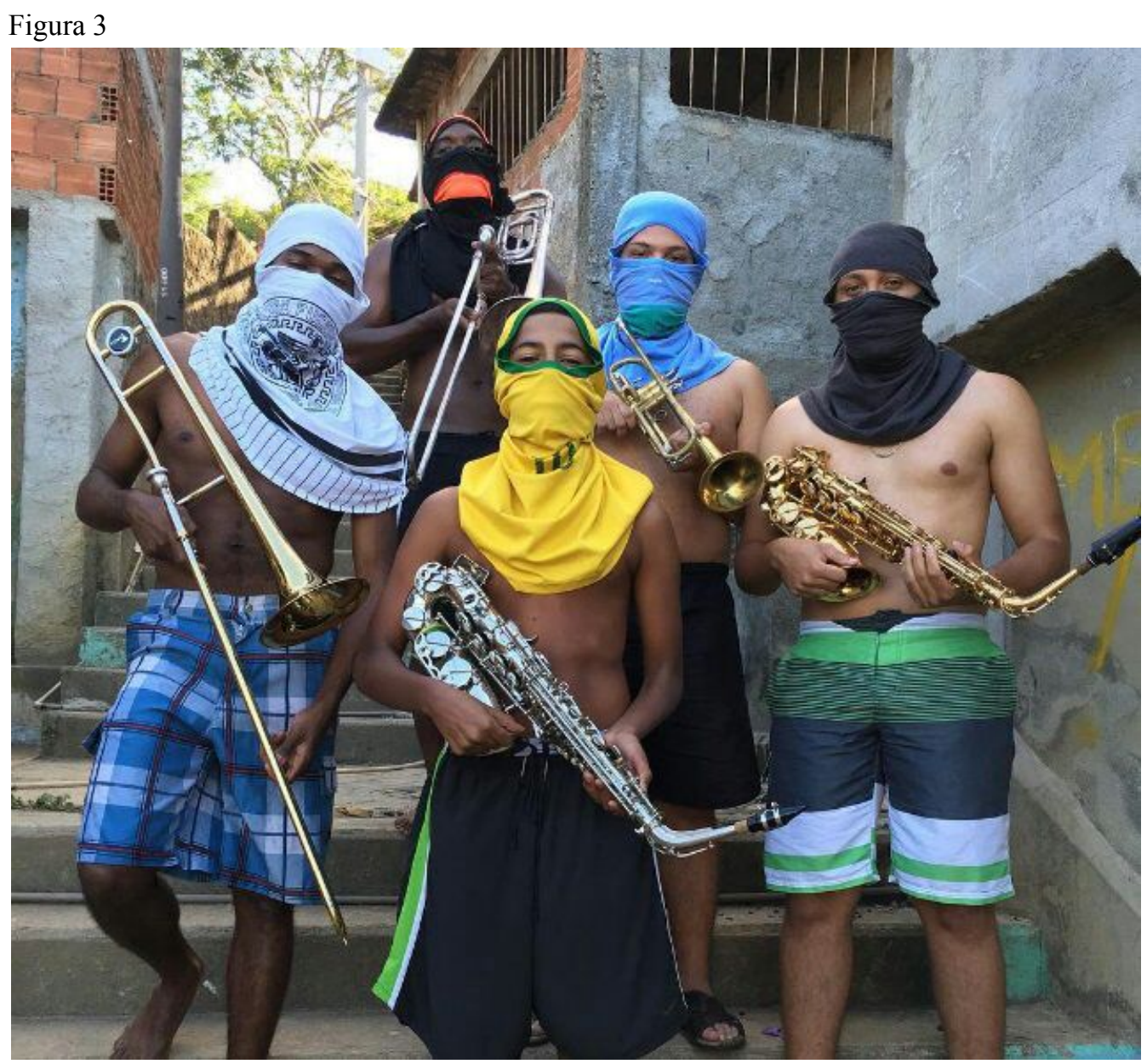

Fonte: G1, Músicos do Morro do Turano.

Ana Flor Fernandes Rodrigues, Rairan de Almeida Silva

Revista Latino-americana de Geografia e Gênero, Ponta Grossa, v. 9, n. 2, p. 293 - 303, ago. / dez. 2018. 


\section{Ressignificação do Ensino a Geografia}

O ensino da geografia sobre a construção do espaço geográfico nos permite trabalhar com representações. Logo, é possível cogitar que um corpo, um sujeito, um jovem negro com um instrumento na mão não só representa parte do que é tido enquanto paisagem de uma favela como questiona um estigma que é atribuído a partir de um imaginário social racista sobre determinados ensaios paisagistas.

A figura $3^{2}$ desse texto projeta uma proximidade da realidade na busca de um conhecimento que, muitas vezes, se distancia do ensino de geografia. Dos recursos didáticos usados em sala, como o livro de geografia que comete muitos erros ao distanciar o sujeito do seu local por conta de um mercado capitalista que insiste em um lucro violento.

O corpo precisa ser visto como espacialidade, ponto de partida e dispositivo que não só está inserido em determinado contexto, mas que faz parte de sua construção. É exatamente sobre isso que estamos querendo falar quando sinalizamos sobre a Favela da Rocinha e os garotos do Morro do Turano e seus desdobramentos (figura 4).

Figura 4 - Lia de Itamaracá: mulher-paisagem

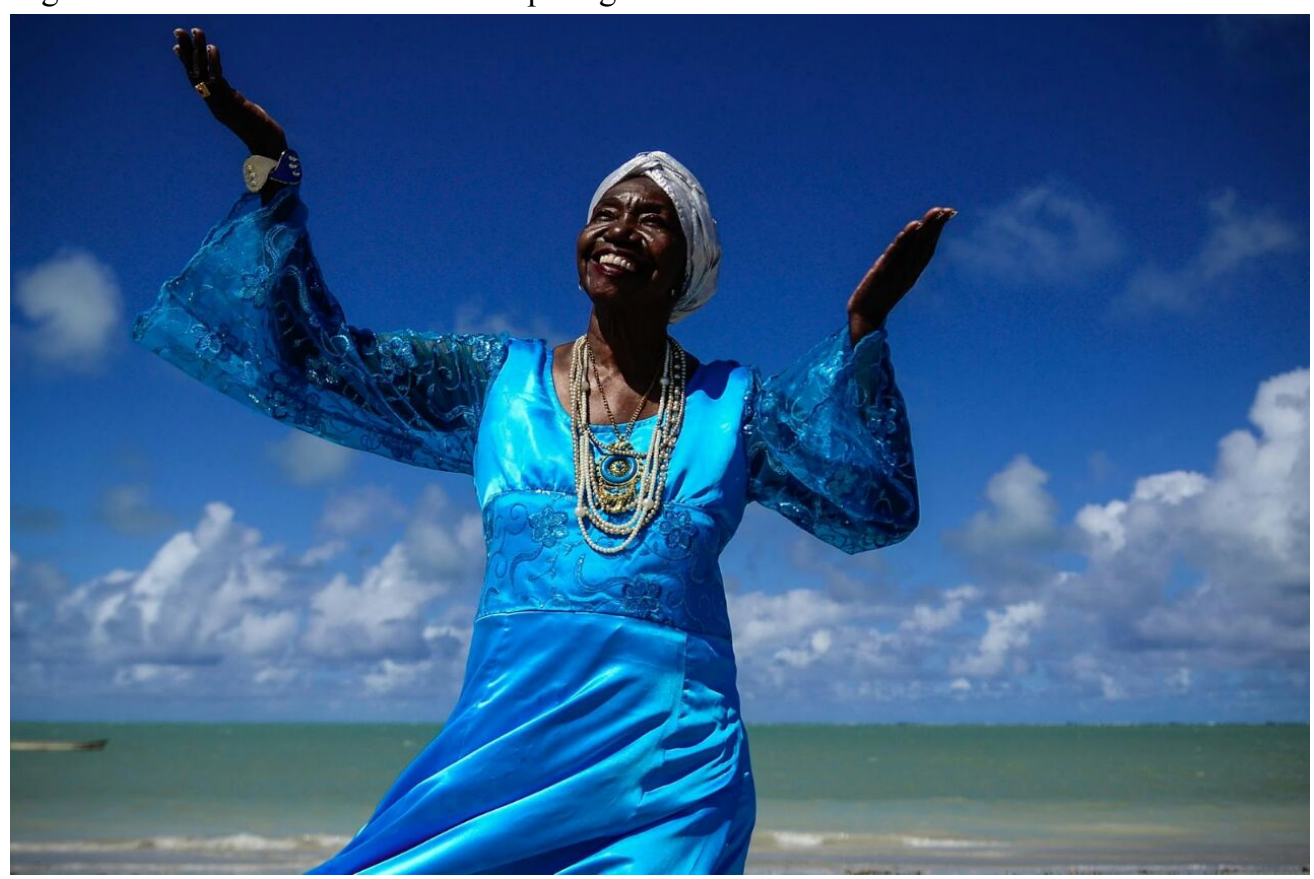

Fonte: Alfeu Tavares.

Pensar Ilha de Itamaracá é, indispensavelmente, pensar Lia de Itamaracá. Patrimônio vivo e cultural de Pernambuco. Essa foto (04), mais uma vez, nos consente o exercício de como a ressignificação do ensino de geografia, mais especificamente da temática de paisagem, se torna possível quando decidimos usufruir de artefatos que se fazem presente na história dos nossos bairros, cidades, estados, países, e ilhas como a de Itamaracá. O que seria de Lia, mulher negra, cantora atemporal, sem a Ilha de Itamaracá? Ou melhor: o que seria de Itamaracá sem a presença de uma mulher ilustre que tráz consigo uma força de mudança através de uma cultura carregada de afeto?

2 Imagem retirada de uma notícia do G1 onde jovens de grupo musical do Morro do Turano seguram instrumentos musicais no lugar de armas. Acessar em: https://bit.ly/2CQmaAM. 
Geografia, Paisagem e Corpo: o Corpo Enquanto Parte do Processo de

Ressignificação do Ensino a Geografia

\section{Algumas Considerações: 0 'Último' Toque}

Incorporar novos conhecimentos é uma tarefa difícil que necessita constantemente ser exercitada. O ensino defasado de geografia nas escolas brasileiras cria barreiras, através de uma estrutura sucateada, que tenta impossibilitar novos horizontes. Entretanto, uma das tarefas que temos na vida docente, é criar estratégias de fugas. Mecanismos de conhecimentos que nos possibilitem driblar, com ousadia, certas problemáticas.

Aplica um olhar que ressignifique que o ensino de geografia é uma urgência. Prontamente, a paisagem se torna um caminho viável. Os debates contemporâneos sobre corporeidades se potencializam quando o assunto é lugar, espaço, território, paisagem, e esses são movimentos que admitem a interdisciplinaridade entre as áreas.

Posto isso, acreditamos que hoje, mais do que nunca, as possibilidades estão batendo, com força, em nossas portas. Corajosamente, arquitetar novas narrativas, mirando metodologias diferenciadas é propor para o corpo a paisagem, assim como para a geografia, que nem tudo está tão distante quanto se parece. Em outras palavras: o corpo, talvez, seja tão paisagem, quanto à paisagem, quem sabe, seja corpo.

\section{Referências}

ALVES, J. J. A. A contribuição de Josué de Castro no estudo e combate à fome e sua repercussão científica e política na geografia. Revista de Geografia, v. 25, n. 2, p. 98-112, mai/ago. 2008.

CASTRO, J. Geografia da Fome - O dilema brasileiro: pão ou aço. Rio de Janeiro: Edições Antares, 1984.

FOUCAULT, M. A arqueologia do Saber. Tradução livre de Luiz Felipe Baeta Neves. Revisão de Ligia Vassalo. Petrópolis: Vozes. 1972.

Vigiar e Punir: nascimento da prisão. Tradução de Lígia M. Pondé Vassalo. Petrópolis: Vozes. 1987.

PERNAMBUCO. Parâmetros Curriculares de Geografia - Ensino Fundamental e Médio. Parâmetros para a Educação Básica do Estado de Pernambuco. 2013.

NÓBREGA, T. P. da. Qual o lugar do corpo na educação? Notas sobre conhecimento, processos cognitivos e currículo. Educ. Soc., Campinas, v. 26, n. 91, p. 599-615, Maio/Ago. 2005.

OLIVEIRA JR. W. M. de. Grafar o espaço, educar os olhos. Rumo a geografia menores. Pro-posições, v. 20, n. 3, p. 17-28, Sep./Dec. 2009.

ROCHA, J. C. Diálogo entre as categorias da geografia: espaço, território, e paisagem. Caminhos de Geografia, v. 9, n. 27, p. 128-142, set. 2008. 
Geografia, Paisagem e Corpo: o Corpo Enquanto Parte do Processo de

Ressignificação do Ensino a Geografia

SALGUEIRO, T. B. Paisagem e geografia. Finisterra - revista portuguesa de geografia, XXXVI, n. 72, pp. 37-53. 2001.

SCHIER, R. A. Trajetórias do conceito de paisagem na geografia. Revista RA'EGA, n. 7, p. 79-85. 2003.

TORRES, M. A.; KOZEL, S. Paisagens sonoras: possíveis caminhos aos estudos culturais em geografia. Revista RÁEGA, n. 20, p. 123-132. 2010.

VESENTINI, J. W. A capital da geopolítica. São Paulo: Editora Ática. 1987.

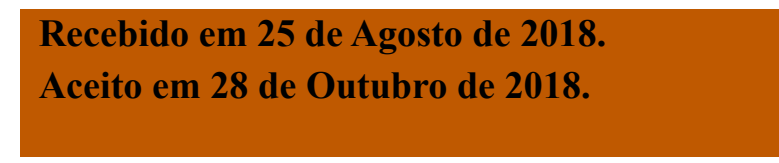

Ana Flor Fernandes Rodrigues, Rairan de Almeida Silva 